\title{
Teoria do teatro e estética teatral
}

\author{
J. Guinsburg
}

o apresentar-me a um concurso de Professor-Titular, em Teoria do Teatro e Estética Teatral, ocorrem-me algumas reflexões sobre a matéria que ministro e o seu papel no conjunto das disciplinas do Departamento de Artes Cênicas, no contexto da Escola de Comunicações e Artes da Universidade de São Paulo.

Tendo desenvolvido toda minha atividade de professor na Escola de Arte Dramática, no Setor Teatro e no atual Departamento de Artes Cênicas da ECA, e dado o fato de a minha carreira acadêmica ter evoluído, nas diversas titulações, em função do Teatro, é claro que meu ângulo de visão está marcado por esta inserção. É bem verdade que, por minha formação, como já descrevi antes, e pelo trabalho que sempre realizei em diferentes áreas, como o jornalismo, a edição e a atuação comunitária, estive em contato com problemas e práticas de várias espécies, cuja repercussão sobre o meu modo de ver não devo menosprezar. Em todo o caso, tais aspectos, no presente âmbito, não precisam ser examinados, apresentando valor específico apenas na medida em que tiverem sido, de alguma forma, incorporados à preocupação com a matéria que ensino.
A Estética Teatral já constava do currículo da Escola de Arte Dramática na época do Dr. Alfredo Mesquita e, independentemente dos temas esparsos abordados por conferencistas ou das questôes particulares ventiladas por professores de outras disciplinas, como foi o caso de Décio de Almeida Prado, Sábato Magaldi, Augusto Boal e Heleny Guariba, entre outros, coube a Anatol Rosenfeld lecioná-la em cursos brilhantes que ficaram na memória de quantos tiveram o privilégio de assisti-los. E ainda hoje, nesta Escola, há quem pertença a este rol.

Não se tratava de um programa detalhado por ele de modo sistemático. Como era de seu gosto, dentro de um esquema solto mas consistente, e pautado pela abordagem filosófica na qual primava, graças a seus amplos conhecimentos e à sua incomparável argúcia crítica, levantava, numa seqüência lógica, itens e questões de importância para a compreensão e a interpretação do fenômeno estético de que o Teatro era manifestação. Infelizmente, não fui seu aluno nessas aulas e nem sequer tive com ele sessões de estudo ou discussões organizadas sobre o assunto. Mesmo no minucioso exame que fez da Estética de Hegel, ao fim dos seminários de filosofia que realizava em minha casa, o tópico

J. Guinsburg é professor emérito do Departamento de Artes Cênicas da ECA-USP. 
de Arte Dramática não chegou a ser tratado. Assim, tudo o que eventualmente aprendi dele, nesse particular, afora aqueles elementos que por certo me transmitiu ao longo de numerosas conversas informais, proveio principalmente $\mathrm{da}$ leitura de seus escritos sobre dramaturgia e espetáculo teatral, em cuja análise sempre entreteceu considerações estético-estilísticas, e sem dúvida, do estudo de seus quatro ensaios ímpares, a meu ver, sobre a estrutura da obra literária, a literatura e a personagem, o fenômeno teatral e a teoria dos gêneros em seu livro sobre o teatro épico. Destes textos pude depreender então que se devia atribuir à Estética Teatral um espaço próprio, com estatuto autônomo.

Um outro impulso na mesma direção, embora vinculado a preocupações menos especulativas, foi o que recebi de Sábato Magaldi, que, entre muitos ensinamentos, proporcionoume alguns itens fundamentais de uma bibliografia básica nesse campo, como as obras de Souriau, André Veinstein, Sylvain Dhome, Henry Ghéon e Henry Gouhier, para citar alguns.

Entretanto, em que pese a relevância de tais subsídios e dos elementos que fui colhendo no correr do tempo, ao contato com as obras de Roman Ingarden, Mikel Dufrenne, Roland Barthes, Jakobson etc., ou do esboço de estruturação dado à disciplina na $\mathrm{EAD}$, o único antecedente imediato e concreto que eu dispunha na ECA, ao assumir em 1970 o curso de Estética Teatral, depois de ter lecionado Crítica Teatral, eram as aulas que Anatol Rosenfeld (10 semestre) e Sábato Magaldi ( $2^{\circ}$ semestre) haviam ministrado em 1969, num curso formalmente sob minha responsabilidade. Tratava-se de um conjunto de preleções que abordava pontos significativos da Estética Teatral e da Teoria do Teatro, mas que não se prendia a um programa regular. Ora, a minha tarefa, desde o início, se fazia mais árdua, visto que surgiu, como era inevitável, a exigência de o professor responsável pela disciplina estabelecê-la em termos de um programa curricular. Não dispondo nem da erudição filosófica de Anatol Rosenfeld, nem dos conhecimentos teatrais de Sábato Magaldi, e não tendo ainda uma visão mais abrangente do campo de estudos, precisei enfrentar o problema por outra via.

Perguntei-me o que seria necessário para que a Estética Teatral exercesse a sua função precípua e se tornasse uma ferramenta útil para o entendimento do fenômeno teatral pelos alunos em seu todo. Desde logo pareceu-me que não poderia pensar a matéria, do ponto de vista do ensino, a não ser na sua relação com o produto último, didático e artístico, de um curso de Teatro, ou seja, a obra teatral. E por obra teatral entendia não apenas o escrito literário, os diferentes elementos que se cruzam e se condensam nele, em termos dramatúrgicos, cênicos, comunicacionais e filosóficos (éticos, estéticos, culturais, políticos e humanos), nem os gêneros teatrais que são teoricamente agrupados a partir de modalidades literárias ou dramáticoespetaculares, porém a peça de teatro na sua concretude final, isto é, na incorporação e consubstanciação que em todos os sentidos, e por todos os componentes de captação pelo espectador, se processa em seu afloramento no palco.

Só esta realização se me afigurava como o verdadeiro objetivo e objeto do trabalho de ensino teatral. Assim, embora recorrendo a elementos diversos dos estudos estéticos na Teoria da Arte e na Literatura, centrei o meu foco, sem dispensar a referência a seus aspectos menos particulares, na relação interdisciplinar, comunicacional e sócio-histórica, do próprio fenômeno teatral.

Por isso, as questôes de linguagem, estrutura e valor foram por mim articuladas não somente como preâmbulos de suas particularizações na operação teatral e nas subseqüentes construçōes expressivas. Tratava-se, como se verifica, de formular um ensinamento estético voltado especificamente para o teatro em ato. Tal fato, por certo, colocava em jogo as várias teorias que intentam explicá-lo e os diferentes estilos que, no seu curso histórico, o operacionalizaram e o materializaram. Daí a idéia de que a matéria deveria compor-se de cinco segmentos, desenvolvidos em quatro semestres: 1) elementos 
de estética geral e de estética teatral; 2) a idéia de teatro e o fenômeno teatral; 3) as teorias teatrais; 4) os estilos teatrais; 5) teatro e sociedade.

Tal programa, entretanto, mostrou-se demasiado amplo e inviável no quadro de um currículo geral de Teatro ainda em estruturação, marcado por sobreposições e por contradições entre as suas pretensões intensivas e extensivas, entre os seus alvos informativos e técnicos, entre a formação acadêmico-crítica e a preparação para o fazer teatral. E isso em um curso que contava com os alunos apenas durante meio período e que abarcava todas as disciplinas de teoria e prática, mesmo quando diploma visado não era o de diretor ou de professor (e posteriormente o de ator) de teatro, mas sim o de dramaturgia ou o de crítica, que mais tarde vieram a ser conjugados no de teoria do teatro.

A consequiência inevitável foi a redução desse programa, que passou a ser ministrado em dois semestres. A diminuição na carga horária trouxe, é evidente, prejuízos para o ensino extensivo dos conteúdos introdutórios, isto é, os da Estética senso lato. Cumpriria focalizá-los, a meu ver, em outro curso, precedente, como disciplina básica das áreas de artes, para o preenchimento dos conceitos essenciais e para o conhecimento da história das idéias e principalmente das grandes doutrinas filosóficas, bem como da filosofia da arte.

É claro que um maior domínio desse repertório geral deixaria o estudante menos despreparado e menos surpreso, ao defrontar-se com o vocabulário, as inter-relações e as aplicaçôes de idéias e noções que ocorrem em um terreno como o da Estética e Teoria do Teatro, mesmo quando estudado sem ênfase especulativa. Todavia, vale registrar que, nesse particular, deve-se contar também com o fato de que nunca deixa de haver - pelo menos tal tem sido a minha experiência nas sucessivas turmas - um percentual, até nada desprezível, de alunos que, por predisposição ou interesse, se não por preparo anterior, domina com rapidez incrível o glossário terminológico e conceitual de importantes aspectos da filosofia e da estética.
Seja como for, o corte na programação também trouxe algumas vantagens. A condensação obrigou-me a repensar os conteúdos teóricos em função estrita da substância teatral, o que, se resultou em tratamento menos pormenorizado do ponto de vista intrínseco e crítico das doutrinas, permitiu abordagem mais cerrada e interiorizada dos elementos e dos referentes propriamente teatrais, ensejando uma explicação, uma aferição e uma contextualização mais imediatas do processo e dos componentes do fenômeno teatral em si e no seu entrelaçamento com outras formas de comunicação artística de massa, como o cinema e a televisão.

No transcorrer destes anos e das discussóes que mantive com alunos dentro da sala de aula, dos inúmeros seminários em que eles debateram os tópicos do curso e, fora da sala de aula, nas trocas de opinião e durante os trabalhos de orientação, pude constatar que, na medida em que a familiarização dos estudantes com os temas filosóficos e os problemas interpretativos aumenta e que sua perplexidade ou alheamento iniciais se desfazem e se convertem em interesse (e, em teatro, a paixão pelo que se faz é pulsão natural), as indagações teóricas e o exercício crítico põem-se a desempenhar um papel crescente, mesmo se não percebido como tal, nas atividades artísticas que empreendem. Seu gosto pela novidade, pela experimentação e pelo vanguardeiro, que é inerente à sua fase de vida, encontra, justamente aí, no discernimento e na descoberta dos construtos mentais, das intersecçôes e distinçôes de idéias e de tendências, um de seus alimentos estimuladores preferidos. Não se trata apenas desta ou daquela corrente significativa ou personalidade excitante: Brecht, Stanislavski, Grotowski, Antunes, Gerald Thomas, Teatro do Absurdo, Living Theatre, teatro antropológico e performático de todos os tipos. Isso vai por si. O importante é que eles começam a cruzar e a testar, por conta própria, com materiais derivados quer daquilo que é considerado tradicional, quer de todas as ourivesarias ou lantejoulas do inusitado, para dizer, e amiúde não chegam a dizê-lo, ou o fazem 
mui canhestramente, algo de original e próprio. Para tanto, investem em como que sínteses, inadvertidas freqüentemente, não só procedimentos e práticas não firmados, ou sequer devidamente adquiridos, porém a capacidade crítico-analítica e as curiosidades das estranhezas teóricas que lhe restaram de seus estudos, leituras e debates em literatura, história, teoria das comunicações, sociologia, psicologia e - por quê não? - estética e teoria do teatro.

É evidente que, em termos mais amplos, este registro não oferece grandes novidades, pois pertence à experiência comum de quase todos os professores que lidam com jovens universitários. Mas interessa-me aqui, salientar o efeito instigador que uma disciplina tão carregada de pensamentos abstratos, como é a Estética Teatral, pode desempenhar. Não é necessário reiterar que, ao lado deste papel, ela precisa exercer também dois outros, da maior importância: o de transmitir informações pertinentes e o de formalizá-las pela discussão rigorosa. $\mathrm{O}$ peso destes, no meu entender, cresce e deve ser enormemente incrementado no trabalho de pós-graduação, exatamente dentro do espectro de questôes abrangidas pela área estético-teatral. Se um alto grau de liberdade, que pode até afigurar-se anárquica, merece, creio eu, estímulo, pelo menos como meio de incentivar as primeiras sínteses pessoais de idéias e de iniciativas artísticas, no período de pós-graduação, em contrapartida, a exigência da propriedade das conceituaçôes, da fundamentação dos argumentos, da verificação dos dados e da adequação do discurso precisa prevalecer, sem dano, é claro, ao lugar a ser reservado à criatividade, à invenção, à ousadia e à atração pelo novo.

Foi com esse enfoque que tentei orientar os meus pós-graduandos. Não sou juiz imparcial dos resultados, mas nutro a esperança de que o conjunto de dissertaçôes e teses elaboradas por eles, desde o momento em que fui credenciado, não tenha fugido muito deste alvo. Sou com freqüência objeto de brincadeiras de meus colegas que ironizam o fato de vários de meus orientandos haverem produzido textos volumosos; na verdade, isso se deve mais à fecundidade deles do que a algum incentivo deliberado de minha parte. Aliás, muito pelo contrário, em meus escritos pessoais tendo a ser menos extenso, inclusive pela natureza ensaística que em geral assumem. De toda maneira, se os trabalhos elaborados com tanto alento não forem verborrágicos, o que de fato não me parecem, nem tem sido essa a opinião das bancas examinadoras, então o motivo das largas análises e exposiçôes deve ser fruto do empenho e da motivação de seus autores. Mais ainda, tenho a impressão de que são obra também de um certo pioneirismo nos estudos de Teatro, no mínimo, em termos nacionais. Os já numerosos e variados assuntos que foram tema de pesquisa, no CAC, formam, a esta altura, uma biblioteca especializada e de nível, de consulta e de referência indispensável para o estudioso. Não vou arrolar os títulos que a compõem e que dizem respeito a quase todas as áreas e boa parte das interfaces das artes cênicas, sobretudo em suas manifestações em nosso país. Mas, para cingirme àqueles que de algum modo se relacionaram comigo e que, portanto, até certo ponto refletiram algumas de minhas preocupações com a Estética, a Teoria do Teatro e a Linguagem Teatral, cumpre-me ressaltar a contribuição de vários de meus pós-graduandos, com trabalhos que não só resgatam capítulos da história do movimento teatral moderno de São Paulo e do Brasil, ou que estudam, sob um novo prisma, a dramaturgia de figuras seminais do teatro nacional, como enfrentam a análise de problemas candentes da arte do ator na "época da reprodutibilidade técnica", da estética da direção, das correntes cênicas atuais até o happening e a performance, e do teatro-educação.

Por outro lado, o acompanhamento do processo de elaboração destas dissertações e teses e o constante debate em torno de seus temas repercutiram por certo em meus próprios trabalhos. Assim, se o texto de meu doutoramento estava voltado mais para a literatura e apenas associava a ela o teatro, o mesmo não aconteceu com Stanislavski e o Teatro de Arte de Moscou. 
Este estudo, que apresentei em minha livredocência, procurava conjugar um esboço da evolução artística do mestre-encenador russo com uma análise de seus compromissos naturalistas e de sua simbiose com a dramaturgia de Tchekhov, estando endereçada diretamente a problemas centrais de encenação contemporânea. Algo semelhante pode ser afirmado com respeito aos vários estudos que redigi sobre os grandes do palco russo e soviético dos primeiros decênios do século XX, e de uma espécie de mise au point teórica que empreendi em um pequeno trabalho sobre o Teatro do Gesto e no ensaio de estilística do ator que escrevi com Maria Thereza Vargas sobre Cacilda Becker. Não hesito tampouco em apontar igual motivação até nos artigos que publiquei acerca das origens e do desenvolvimento do Teatro Judeu e, mais ainda, na minha pesquisa, tradução e reflexão crítica a respeito dos escritos teóricos e dramatúrgicos de Leone de Sommi. Diria inclusive que várias de minhas traduçóes, como a Idéia do Teatro, de Ortega y Gasset, o Teatro Leste \& Oeste, de L. Pronko, e a coletânea de Semiologia do Teatro, que organizei com Teixeira Coelho Neto e Reni Chaves Cardoso, bem como alguns textos que verti para esta antologia, encontram-se na mesma linha. Poder-se-ia ainda considerar que mesmo a minha atividade como editor também não escapou a esse apelo, posto que tenho dispensado uma atenção não pequena à bibliografia teatral, tanto estrangeira quanto nacional, conforme comprovam as publicações da Editora Perspectiva neste campo.

Como conclusão para as observações que acabo de tecer, permito-me salientar que, embora não tenha me desvinculado dos vários centros de interesse em torno dos quais desenvolvi o meu trabalho intelectual, ao longo dos anos verificou-se, de minha parte, uma concentração crescente não só na área teatral, como mais especificamente nas questôes relacionadas com as disciplinas a que me dediquei como professor. É natural, pois, que a mesma ênfase se apresente em alguns projetos de estudo que venho desenvolvendo. Um deles é o de concluir a série de ensaios sobre a estética dos renovadores da cena russa e reuni-los em livro. Penso também reescrever e editar em forma de seminários as aulas de meu curso de Estética Teatral I. Além disso, eu e Nanci Fernandes pretendemos concluir no próximo ano o trabalho sobre a contribuição crítica e teatral de Décio de Almeida Prado. Inscrevem-se no mesmo contexto as traduções que estou preparando do livro de Richard Boleslavsky, Acting, sobre o método do ator, bem como de escritos de Nietzsche e Pirandello, e levar a cabo, finalmente, o meu antigo anseio de verter para o vernáculo algumas das principais obras da dramaturgia judaica.

Diante de tudo o que expus até agora, poder-se-ia julgar que o trabalho na minha disciplina vem atingindo plenamente os seus propósitos. Mas não é o que penso.

Independentemente de futuros desdobramentos curriculares ou reformulações de conteúdo, um dos ângulos que mereceria maior cuidado e desenvolvimento é o que diz respeito ao entrosamento mais orgânico e mais ativo da Estética Teatral com as outras matérias da própria área teórica e, sobretudo, da área prática. O objetivo seria, de um lado, chegar a um tecido mais entrelaçado e estendido no que tange ao repertório de conhecimentos veiculados e, de outro, efetuar a aplicação de diferentes segmentos do arcabouço teórico às exercitações em andamento nos ensinamentos práticos.

Se fosse possível promover um programa circunstanciado nesse sentido, creio que o ganho não seria apenas da Estética Teatral, pois, desde logo, as seguintes vantagens são descortináveis:

A carga expositiva desta disciplina e de outras integrantes da Teoria do Teatro poderiam sofrer um redimensionamento. Não para reduzir o seu conteúdo teórico e a reflexão crítica, mas, ao contrário, para ampliá-los através de um conjunto de trabalhos e exercícios dirigidos em pequenos grupos e de estudos individualizados, sob a orientação dos professores; mais ainda, os vários docentes da área ver-se-iam, desta maneira, envolvidos em uma atuação interdisciplinar e, em momentos previamente selecionados, 
encaminhá-la-iam para o debate dos principais pontos de intersecção das disciplinas intervenientes, sem que isso devesse afetar a liberdade de condução e o modo pessoal de concepção que constituem princípios básicos da atividade do professor universitário.

As realizações da área prática suscitando, como suscitam, questões que não se restringem ao campo técnico e às operaçóes da produção e vão, desde a estética da direção e do ator, até todo tipo de problemas dramatúrgicos, filosóficos e históricos, seriam motivos de exames conjugados, sob o prisma específico do interesse do momento, em oficinas organizadas pelas duas áreas nas matérias implicadas; este enfoque permitiria um estudo tópico que as disciplinas teóricas e, no caso em pauta, especialmente a Estética Teatral requerem para uma transmissão imediatamente perceptível e uma captação capaz de mobilizar, de pronto, o interesse do aluno; isto, para não mencionar a extensão que por aí se daria aos substratos teóricos e os subsídios práticos que assim adviriam.

A propósito, convém lembrar que algo de natureza similar já estava na perspectiva dos experimentos com os ateliês, que se desenvolveram, sob a minha direção, no antigo Setor de Teatro do CTR da ECA, em 1973, e que, no seu malogro, por falta talvez de uma estrutura de apoio adequada, de um prosseguimento no tempo, de uma discussão e avaliação críticas construtivas e aptas a indicar soluçôes mais eficazes, não deixaram, apesar de tudo, de causar viva impressão em alunos e professores que deles participaram, tendo havido mesmo, no decorrer dos anos, repetidas sugestôes no sentido de que a tentativa fosse retomada.

É certo que, em última análise, esta proposta tinha - e eu diria que continua tendo no presente contexto - um objetivo em mira: o de uma instituição de ensino teatral altamente integrada e capacitada a promover em grau máximo a formação não só de um profissional polivalente da cena, mas, sobretudo, de um homem de teatro que reúna no seu saber e fazer a teoria e a prática.
Ao invocar novamente esta idéia, sei que não estou primando pela originalidade. Múltiplas colocações nesta direção foram formuladas desde Stanislavski e Copeau até as modernas escolas de teatro. Não tenho dúvida também de que ela está, clara ou insinuada, no espírito da maioria dos professores do CAC e da EAD. Entretanto, eu não poderia deixar de aproveitar a oportunidade que este memorial me oferece para expor um ponto de vista sobre uma didática e uma metodologia do ensino de teatro e, em especial, da Estética Teatral e da Teoria do Teatro, tanto quanto sobre uma filosofia de uma escola da arte do teatro.

Em conseqüência deste modo de pensar, em que a análise teórica e o exame crítico são a contrapartida indispensável do fazer, não posso compartilhar da posição daqueles que defendem, em nome de uma visão supostamente mais atualizada das artes na época da veiculação de massa, uma estrutura curricular que pulveriza a especificidade de cada arte, remetendo-a a uma pasteurizadora abstração estrutural e semiológica, a pretexto imagístico e comunicacional. Não que eu desdenhe as contribuições das pesquisas estruturais e semióticas, da teoria da informação e da comunicação em caráter particular ou interdisciplinar, nem da sociologia dos fenômenos culturais ou das extraordinárias liçōes da lingüística e da antropologia de nosso tempo, ou que relegue a segundo plano o seu impacto e o seu alcance na ação comunitária, nas condições da sociedade brasileira. Porém, segundo creio, quanto melhor realizada e caracterizada a formação do estudante de arte na "sua arte", maior será o seu poder de interagir com outras linguagens, estilos, procedimentos e técnicas, de maneira pertinente, criativa e consciente.

Neste sentido, o ideal de uma Escola de Arte Cênica é, e será sempre, para mim, um Instituto de Teatro que abarque, na sua proposta curricular, todos os ensinamentos que concorrem para a construção artística do espetáculo teatral e para a habilitação pragmática e teórico-crítica de seus fautores. 
É bem verdade que, nas atuais circunstâncias e na ideologia produtivista e tecnocrática ora dominante na USP, um projeto deste tipo teria de enfrentar tantos entraves burocráticos que, mais do que uma idealização, afigura-se, na perspectiva de hoje, quase uma utopia. Contudo, muitas vezes a utopia parece guiar os passos da práxis. Por isso, no presente caso, não se deveria pô-la de lado. Embora venha a exigir, provavelmente, o longo caminho de um processo incorporador, vale a pena trilhá-lo, acredito. De minha parte, alimento a esperança de que, por exemplo, os atuais Departamento de Arte Cênicas e Escola de Arte Dramática, de algum modo integrados, dêem o primeiro passo para tornar mais orgânico e completo o estudo de Teatro nesta Escola. 